\title{
BONET NAVARRO, ÁNGEL (2009). El juicio sobre la suficiencia en la ejecución de las Sentencias de condena dineraria. Navarra: Thomson - Aranzadi, 190 pp.
}

Esta obra del catedrático de Derecho Procesal de la Universidad de Zaragoza, Ángel Bonet Navarro, es de aquellos libros que deben leerse una y otra vez, en atención a su rigurosidad científica. El trabajo científico invita a quienes nos dedicamos al proceso -sea civil o penal- a hacer lectura de cuestiones procesales que en una norma legal pasan casi inadvertidas. Este es el caso de la suficiencia en la ejecución. La LEC de España utiliza el vocablo de suficiencia o insuficiencia; de suficiente o insuficiente en diversos preceptos. Lo mismo ocurre en nuestro ordenamiento jurídico en el Código de Procedimiento Civil, en donde se utiliza esta palabra en toda su extensión, siendo en la ejecución su mayor aporte.

La obra monográfica del profesor Bonet se estructura en seis grandes capítulos, más un capítulo introductorio y las conclusiones pertinentes. El primero lo dedica a la suficiencia en el ámbito jurídico, estudiando el criterio de suficiencia como principio ordenador de conductas jurídicas. En este aspecto nos enseńa que al querer juzgar el grado de acabamiento de una conducta realizada, o de una obra terminada, es preciso compararlas con el modelo o valor, definidos previamente conforme a los cuales han debido ejecutarse aquellas. Así, la comparación de la acción o de lo hecho en concreto con la pauta establecida de forma general proporciona los elementos idóneos para formular el juicio acerca de su desarrollo. Si la acción o el resultado se corresponden exactamente con lo propuesto como modelo, se puede decir que se ha hecho lo necesario para considerar "satisfactorio" una y otro, porque han alcanzado plenamente su fin: han sido bien hechos. Se alcanza la "perfección". Unida a estas dos palabras se encuentra otra que le interesa al autor porque significa haber alcanzado el nivel de la medida completa de lo ejecutado sin necesidad de complemento alguno: esta palabra es "suficiente".

A continuación, el sistema de cumplimiento de las sentencias y la determinación de suficiencia que hace el legislador y las determinaciones particulares para lograrla, ocupan un nuevo capítulo. En esta parte afirma que si la finalidad de la ejecución es dar al ejecutante aquello que el obligado a darlo debió entregar si hubiera decidido, en su momento, cumplir lo impuesto por la norma, es preciso dotar al proceso de ejecución de instrumentos adecuados de los que pueda disponer el tribunal para conseguir en cada caso el fin que interesa, de acuerdo con lo que dispone la norma cuyo cumplimiento se impone -al condenado- a través de una resolución judicial.

Continúa la obra con el análisis de la eficacia y la suficiencia en el cumplimiento de las sentencias, analizando conceptos relevantes como 
son la cosa juzgada, la congruencia y la idoneidad e intensidad del modelo de las actuaciones ejecutivas (suficiencia ejecutiva). En este capítulo el autor es contundente: "las sentencias deben ser eficaces". La eficacia de la sentencia de condena se ampara en la Constitución española (artículo 118: "es obligado cumplir las sentencias") y en otra afirmación normativa regulada en la Ley Orgánica del Poder Judicial: artículo 18.2 "las sentencias se ejecutarán en sus propios términos". Cuando una sentencia definitiva dictada en un proceso jurisdiccional aplica el mandato de la norma jurídica que no se ha cumplido, decide que se cumpla aquello que dispone la norma. Por lo tanto, a partir de este momento lo que debe cumplirse directamente no es la norma jurídica, sino la sentencia.

La configuración de la suficiencia en la ejecución dineraria abre un nuevo capítulo de esta obra. La firme convicción de que nada debe embarazar la actuación ejecutiva se halla matizada con la imposición de una regla que ha de observarse para evitar tanto el perjuicio del ejecutante al conseguir menos de lo que corresponde, como el del ejecutado al tener que soportar un sacrificio desproporcionado a su responsabilidad. Precisa Bonet Navarro que las razones que explican el modo de ser del proceso de ejecución siempre tienen que ver con la reducción del daño que ha de sufrir el deudor y el mayor provecho en cuantía y rapidez que ha de obtener el acreedor. Todas las actuaciones que componen el proceso de ejecución (incluida la traba del embargo) deben tender por una parte a aumentar el provecho del ejecutante $y$, por otra, a reducir el coste del ejecutado. Entonces, el juicio de suficiencia sirve para determinar el equilibrio entre el provecho que busca el ejecutante y el coste que ha de soportar el ejecutado. El sujeto procesal encargado de formular el juicio de suficiencia es el juez ejecutor, el órgano jurisdiccional que conoce de la ejecución.

También los elementos determinantes de la suficiencia para el embargo de bienes son objeto de una detallada investigación en el capítulo siguiente. Así expresa que en el proceso de ejecución dineraria el canon con el que se ha de medir la suficiencia es la cantidad por la que se despacha la ejecución, porque la resolución judicial que ordena despachar ejecución es el acto procesal que determina el desarrollo del proceso ejecutivo. En materia de condenas no dinerarias el canon de suficiencia del embargo se debe ajustar a la cantidad suficiente para asegurar el pago de eventuales indemnizaciones sustitutorias y las costas de la ejecución.

Termina la obra con la suficiencia en otras fases del apremio, en particular lo que se refiere a la realización forzosa y al pago. A juicio del autor, el canon o criterio de suficiencia, como regla rectora del embargo en un proceso de ejecución, se expande también a los actos procesales posteriores. Tales actos, señala, "no son consecuencia de un puro mecanicismo procedimental incontrolados, sino que deben sujetarse al juicio estable- 
cido de diversas maneras para tutelar tanto los intereses del ejecutante como los del ejecutado".

En conclusión, estamos frente a una obra de lectura obligada, que manifiesta la opinión del autor de manera precisa y determinante, sobre un tema trascendente y esencial en materia de ejecución, y del proceso civil en general.

FERNANDO ORELLANA TORRES

Profesor de Derecho Procesal de la Escuela de Derecho de la Universidad Católica del Norte, sede Antofagasta. Diplomado en Estudios Avanzados en Derecho Procesal por la Universidad de Zaragoza (España). Doctorando en Derecho por la misma Universidad. Correo electrónico: forellana@ucn.cl 